\title{
O conceito de autoria em Walter Benjamin
}

\author{
César Colera Bernal*
}

Resumo: As características fundamentais com que Benjamin fez confinar a noção de autoria estão centradas na conferência "O Autor como Produtor" (1934). Este conceito o constrói Benjamin em crítica acerba contra o tipo do pseudo-autor que, militando nas filas da revolução, serve em sua atividade à lógica do capital. O pensamento de Benjamin desemboca na compreensão do que é a marca de autenticidade de um autor, inspirada no surrealismo e no teatro de Brecht. Concluímos relatando evidências contemporâneas de eu a proposta política benjaminiana está mais viva do que em qualquer época.

Palavras-chave: pirâmide de poder - autoria - literalização - tecnologia liberdade de expressão.

Abstract: We went examining the fundamental characteristics with that
Benjamin made to confine the notion of authorship, focusing in the conference
"Author as a producer" (1934). This concept is built by Benjamin as a bitter critic
against the pseudo-author type that, militating in the revolutionary lines, serves
in fact, in his activity, to capital logic. Benjamin's reflections flow into the
understanding of what is the mark of an author's authenticity, inspired in the
surrealism and in Brecht's theatre. We concluded relating contemporary
evidences of that the Benjamin's political proposal is more alive in any time.

Keywords: power pyramid - authorship - literalization - technology - freedom. 
O título deste artigo é uma traição ao pensamento de Benjamin. Supõe a pretensão de se poder incluir numa categoria formal - nessa "coisa rígida e isolada", como ele próprio nos diria - a maneira como se mostra a realidade viva da autoria na reflexão benjaminiana. De fato, nosso autor não define, não fecha, em fronteiras artificiais, os temas que aborda, senão que insinua, avança contextos, sugere aproximações, contrapõe aspectos, busca e flerta com o oposto, decompõe e remonta com elementos heterogêneos tudo sobre o que sua imaginação discorre. O fluxo do seu pensamento desenha sinuosos arabescos; segui-lo é se introduzir num labirinto impuro, de espelhos convexos e de imagens em fragmentos, onde clarividentes projeções do futuro se refletem deformadas nos relatos sobre as ruínas da história; onde as duras engrenagens do materialismo entram em secreta harmonia com místicas auras; onde o paradoxal se encontra com o sistemático; o dialético com o categórico; o alegórico com o prosaico; e o autor com o produtor.

Pois bem, repare neste último entrelaçamento: autor-produtor. É aqui que, segundo acreditamos, se revelam, de forma particularmente emblemática, tanto o modo de Benjamin raciocinar e escrever, como a sua proposta política de edificação de novas relações sociais de produção. Isto é, é na tensão que resulta desse par dialético que simultaneamente se nos mostra a caleidoscópica forma em que ele pensa e o por ele pensado sobre a realidade que o cerca, provocando a complexa trama da sua reflexão.

Esta trama nós a perseguimos em "O autor como produtor", 1 onde, em 1934, no auge do seu alinhamento ideológico com a revolução soviética, pronunciou uma conferência sob esse lema para intelectuais progressistas, na sede do Instituto para o Estudo do Fascismo. O que então ele disse não pode ter agradado todo mundo, como não o faria hoje, pois, no que a Alemanha da conturbada República de Weimar e nossa época de mercado global possam ter ainda em comum, está certamente o fato de que grande parte dos que se auto-consideram progressistas mereceriam antes o qualificativo de reacionários, no exigente juízo de Benjamin.

Compreender bem este julgamento, na medida em que resulta de uma explícita resistência contra a mentalidade burguesa, nos exige apresentá-la. Ou melhor, representá-la - a ela e ao mundo a que esta deu lugar. E nós o faremos sugerindo uma imagem que os simbolize, e que, ao mesmo tempo, os descreva, caracterizando-os, explicitando sua lógica interna e seus traços definitórios. Que imagem é essa? A do organograma, a da pirâmide de poder. Você certamente já viu mais de uma. Um mosaico de quadrículas ligados por linhas verticais, representando quem manda em quem. Em forma de funil, no topo só há espaço para uns poucos: uma elite a acumular poder, prestígio e propriedade. $\mathrm{Na}$ larga base, sob o comando desses, encontra-se o proletariado, triplamente destituído. No meio, os que, mesmo dominados, prosperam nesta configuração social. Pois bem, faça este experimento: ponha idealmente ante si essa imagem, interrompa as impressões preconcebidas que guarda em relação a ela, distancie-se dos sentimentos que lhe provoquei ao lhe contar sobre as pessoas que nela habitam; e deixe-a lhe falar. Ouça-a. Ela, a pirâmide de poder, lhe diz: ordem, racionalidade, limites claros, ou dentro ou fora, ou acima ou abaixo, responsabilidade,

\footnotetext{
${ }^{1}$ BENJAMIN, Walter. Magia e Técnica, Arte e política - Obras escolhidas I (Trad. Sérgio Paulo Rouanet), São Paulo, Brasiliense, 1996.
} 
estabilidade, previsibilidade, equilíbrio, simetria, verticalidade, hierarquia, autoridade, tudo e cada pessoa no seu lugar, um lugar para cada coisa e cada pessoa, identidade, clareza, objetividade, solidez, firmeza.

Agora, sinta. Sinta-se dentro deste mundo e de sua lógica peculiar. Seu sentimento só não será de autêntico e indisfarçável prazer se você não for dos que endireitam a moldura de um quadro torto na casa dos outros, dos que lembram da data de aniversário do seu chefe, dos que se impacientam pela demora do presidente em nomear seu ministério, dos que arrumam suas gavetas, dos que vêem com incômodo a invasão dos estrangeiros e seus costumes exóticos, dos que exigem do outro esperar até o final do filme para comentá-lo, e, sobretudo, mas sobretudo mesmo, se não for dos que lembram aos demais onde começam e terminam suas respectivas funções, seus recíprocos papéis, delimitando competências e responsabilidades. E ao contrário. $\mathrm{Na}$ medida em que se identifique nessas ações, tenha-o claro: para Benjamin, você é um burguês...

Você protesta, claro; e é compreensível seu rechaço. Repele essa idéia e a rebate: você aprecia a ordem, concedamo-lo. Mas não esta ordem. Afinal, sua lúcida inteligência, aparelhada nas teses dos teóricos mais penetrantes, já bem lhe revelou as nefandas contradições internas do cosmo burguês. Mais do que isso: você não se omite, senão que é dos que clamam, reclamam e denunciam, disseminando consignas revolucionárias, provocando nos outros indignação e revolta contra "tudo o que está aí". Bem, aí já é diferente: sua situação é para Benjamim inequívoca: é a de um "burguês de esquerda"... Pois é, ainda um "reacionário", um mero "abastecedor do sistema".

Abastecedor? Isso mesmo; e o argumento de Benjamim é irrebatível. De fato, nosso arguto alemão nitidamente percebe, assombrando-se, a enorme capacidade que mostra o aparelho burguês de assimilar conteúdos que lhe são antagônicos, engordando, diríamos nós, com eles; isto é, transformando-os em mercadorias lucrativas. Daí que boa parte das críticas produzidas contra o modo de produção capitalista e suas contradições não passem, na avaliação dele, de "mímica proletária da burguesia decadente". Em sua atividade, este burguês travestido de revolucionário frui dos benefícios de ocupar um "estamento" na ordem do capital. Desde que ele, cooptado, domesticado, "acomodado confortavelmente [nessa] situação tão inconfortável [...] transforma em objeto de consumo a luta contra a miséria [e] numa festa sua vacuidade abissal" ". Isto é, converte os meios de produção que o capital lhe põe ao alcance em objetos "de prazer contemplativo", em lucrativos artigos de consumo.

Que resta então a você, autor que se auto-define e se sente de esquerda, diante desta diatribe? Talvez invocar a originalidade de seus escritos, a renovada visão em que exprime sua opção revolucionária, a obra-prima de denúncia social que sai de sua pena. Ante isto, Benjamin diria - e lembre-se do lugar em que profere sua conferência: eis aí a que se propõem os fascistas. E com seu amigo Brecht, singular modelo de inspiração nestas questões, acrescentaria: antes você pensasse deficitariamente, pois "do ponto de vista político, o que conta não é o pensamento individual, o talento inventivo, mas a arte de pensar na cabeça dos outros"... ${ }^{3}$ Logo, é precisamente essa sua pretensão de possuir uma personalidade criadora que o impede, obediente à causa proletária, renunciar à sua autonomia, assumindo submissamente as tarefas que esta lhe exige.

Contudo, há intelectuais, há autores, que vão mais longe: vão além do protesto e da denúncia, além da crítica e da indignação pelas injustiças. Esses - é você um deles? ultrapassam essa posição confortável e "dão seu sim de princípio ao combate"; aderem

\footnotetext{
${ }^{2}$ BENJAMIN. Magia e Técnica, Arte e Politica, Opus cit. pp. 130

${ }^{3}$ Ibid, p. 126
} 
ao socialismo aprovando, com "emoção e tristeza" inclusive a "luta de classes homicida". Isso lhes conquista um lugar. Benjamin se pergunta: "Que lugar é esse?" E responde: "o lugar de um protetor, de um mecenas ideológico. Um lugar impossível"... A descrição, evidentemente, está carregada de desprezo. "Não é de admirar", nos dirá ainda, que esse papel "não haja nunca exercido uma influência revolucionária". Quem na realidade você é - um autor burguês decadente - invalida as radicais convicções que você sustenta.

Pode ser que tudo isto o deixe um pouco perplexo ou desanimado. Verdadeiramente, não deve ser lisonjeiro descobrir, se esse for o seu caso, que as qualidades que julga lhe constituírem como autor - e autor engajado na luta de classes lhe situam no vulgar papel de "escritor informativo", um contra-revolucionário dócil às "esferas compartimentalizadas de competência no processo da produção intelectual", 5 fundamentais à concepção e à manutenção da ordem burguesa. Dito com outras palavras: você é "o inimigo"...!

"Compartimentalizadas". Você reparou nesse termo? Considere-o bem porque é a chave para prosseguirmos nosso estudo do conceito benjaminiano de autor. Aliás, já falamos da inadequação inerente à tentativa de tratar da realidade "autor", complexa e dialética, apenas como conceito estático. Tornar-se-ia em estereótipo, em compartimento estanque, fechado sobre si, pobre de referências, isolado, individualizado, solipsista... Como mais diríamos?... Burguês. Claro! Já tínhamos visto que as caixinhas que representam funções na pirâmide símbolo da sociedade burguesa expressam exatamente isso: compartimentalização, separação, definição estática de limites. Aceitemo-lo então: até aqui - desde que toda nossa verve revolucionária só teve o efeito de fortalecer esses compartimentos, essa ordenação artificial de tudo o que compõe o universo burguês - só conseguimos em verdade avançar na caracterização de um tipo de autor; obviamente, o do autor burguês.

Mas, por ser o autor burguês o oposto dialético do autor progressista, sabemos agora ao menos que bastião combater: o bastião-conceito; e, nele, sua mais conspícua expressão política: a função. Função? Não seria "classe", classe social? Não, Benjamin não é homem amigo de categorias macro, imponentes, grandiosas, que ensombram os feitos verdadeiramente significativos das pessoas correntes. Verdade é, porém, que, ao verter suas idéias neste artigo que nos ocupa, se utiliza de macro-sujeitos históricos como "burguesia" e "proletariado". Mas estes só lhe ocupam a imaginação por causa de um estado de espírito peculiar que vale ter em consideração para pôr na devida perspectiva suas afirmações, especialmente as mais radicais. Referimo-nos à iminência que ele vê na derrocada da ordem burguesa e sua substituição pelo "Estado soviético". Aliás, isso deve-o a uma dupla e intensa paixão: pelo credo marxista e por Asja Lacis a mulher de quem o recebeu, antes que esse mesmo Estado a enviasse a um campo de concentração ${ }^{6}$ por ultrapassar os limites prudentes da autoria. Estamos, pois, na época mais militante de Benjamin, prévia aos expurgos de Stalin; uma espécie de fase, perceptível pela infiltração no seu discurso de um palavreado pronto, fortemente ideologizado. Mas, se, como dizíamos, a iminência da reviravolta política o impelia a escolher a trincheira desde a qual lutar, não era contudo razão suficiente para distanciá-

\footnotetext{
${ }^{4}$ Ibid, p. 127

${ }^{5}$ Ibid, p. 129

${ }^{6}$ COETZEE, J.M. As maravilhas de Walter Benjamin, (Trad. Siqueira, R)., pub. orig. The New York Review of Books, vol. 48, $\mathrm{n}^{\circ} 1$, janeiro de 2001, in http://www.cebrap.org.br/imagens/Arquivos/as_maravilhas_de_walter_benjamin.pdf
} 
lo do homem comum; este sim - tal como no dadaísmo, vanguarda artística a inspirar Benjamin - centrava sua atenção.

E, retomando então nosso assunto, devemos dizer: esse homem comum tem, antes que uma classe, uma função. E é exatamente esse homem, assim enquadrado, encaixilhado numa função, reduzido ao exercício de um papel, restringido pelas categorias delimitadoras e de controle do mundo burguês, determinado em suas relações sociais em razão do seu lugar no aparelho de produção - é precisamente este homem, talvez este intelectual, certamente este produtor - que constitui o locus próprio do autor progressista, seu campo privilegiado de ação; ou melhor, de batalha. A missão do autor, do autor progressista - e sua marca de autenticidade revolucionária - consistirão na efetiva transformação dessas relações, dessa estrutura opressivamente racional, dessa hierática arquitetura de ordem, de poder vertical, de onímoda sujeição, que deriva sua força do controle rígido, por uma cresa minoria, dos meios de produção.

"Transformação" é, pois, um conceito central. Benjamin faz repetidas alusões ao mesmo; e à mesma idéia, como no apelo a "modificar o aparelho produtivo" 7 , a "romper sua ligação com a classe dominante" 8 . Significativa é também a utilização repetida do termo "organização", no sentido de reorganizar as relações; assim quando estimula a "vislumbrar caminhos para organizar os trabalhadores no próprio processo produtivo" " . A idéia de que o autor progressista, verdadeiramente solidário com os excluídos, deve se empregar - já desde o lugar que agora ocupa dentro da sociedade capitalista - na construção de uma nova ordem, fica patente na desejada metamorfose do autor em engenheiro (profissão pela que nutria, diga-se de passagem, grande apreço). Revestido da arte própria deste ofício, poderá o autor fazer a "adaptação [do aparelho burguês de produção intelectual] aos fins da revolução proletária" ${ }^{10}$

Chegados a este ponto, devemos tentar, dando um passo mais, precisar o sentido e os modos da transformação que se nos comina a operar. Felizmente, o teatro épico experimental de Brecht nos fornece uma orientação segura. Mais do que isso, deste dramaturgo obtemos uma terminologia e a sua concretização. Obtemos, portanto, teoria e prática, intelecto e matéria - autoria e produção. Mas, se tivermos de escolher um termo para aglutinar esta dupla influência, este terá de ser o de "refuncionalização".

\footnotetext{
"Brecht", nos diz Benjamin, "criou o conceito de 'refuncionalização' para caracterizar a transformação de formas e instrumentos de produção por uma inteligência progressista e, portanto, interessada na liberação dos meios de produção, a serviço da luta de classes. [...] Brecht foi o primeiro [a modificar o aparelho de produção]". ${ }^{11}$
}

A refuncionalização consiste na introdução de inovações técnicas visando derrubar as barreiras convencionais das funções em que o sistema burguês se sustenta. Benjamin o traduz apropriadamente por "fusão". Numa bela e eloqüente metáfora, nos falará da "massa líquida incandescente" na qual serão fundidos os compartimentos conceituais e funcionais burgueses. Que identidade, que fronteira, que aristocrático

\footnotetext{
${ }^{7}$ Ibid, p. 128

${ }^{8}$ Ibid, p. 128

${ }^{9}$ Ibid, p. 136. Cf. também em pp.131 e 133.

${ }^{10}$ Ibid, p. 136

${ }^{11}$ Ibid, p. 127
} 
baluarte, que refratária trincheira sobrevive isolada nessa caldeira revolucionária? É evidente que a fusão tudo abrange. Brecht refuncionaliza, amalgama os elementos primitivos do teatro, eliminando a distância "entre o palco e o público, entre o texto e a representação, entre o diretor e os atores".

As conservadoras "barreiras que acorrentam o trabalho produtivo da inteligência" 12 estão por toda parte. No campo da produção de imagens, a fusão a realizar é a que elimina a divisão entre fotografia e escrita. O progresso técnico que se exige dos fotógrafos é o de "colocar em suas imagens legendas explicativas [que] lhes confiram valor de uso revolucionário" ${ }^{13}$. Note-se, nesta citação, um aspecto essencial ao conceito de fusão; em realidade, o mais essencial: a presença da palavra. A palavra é o nexo entre as funções; é o meio de produção apto a transformar, a mesclar, libertando das suas esferas armilares o prescrito curso das competências. A palavra, em cooperação com "os fatos técnicos de nossa situação atual" (refere-se às possibilidades que apresentam o surgimento do cinema falado, da fotografia, do disco ou do "automático musical"), combina as diferentes formas de criação: "Estamos no centro de um grande processo de fusão de formas literárias, no qual muitas oposições habituais poderiam perder sua força. [... evidencia-se a] esterilidade dessas oposições e a possibilidade de sua superação dialética" ${ }^{14}$. A palavra tem o poder miraculoso de suprimir todas as disjunções - também na música. Aqui, sua refuncionalização poderá "eliminar a oposição entre intérprete e ouvinte [...] entre técnica e conteúdo [transformando] um concerto num comício político" ${ }^{15}$,diz citando Eisler, estreito colaborador de Brecht.

A fusão-refuncionalização, como vemos, se dá através da palavra - não simples palavra ideológica - mas palavra que, tanto propõe como emprega, transformações técnicas capazes de superar as antinomias que agrilhoam o espírito. Neste sentido, Benjamin, recorrendo, bastante ingenuamente, ao exemplo da imprensa soviética (cuja evolução histórica, nada libertária, irá transformá-lo numa amarga ironia) mostra como ali o processo de fusão já, "não somente ultrapassa as distinções convencionais entre os gêneros [literários], entre ensaísta e ficcionista, entre investigadores e vulgarizadores, mas questiona a própria distinção entre autor e leitor" " ${ }^{16}$. Esta citação é especialmente importante: põe-nos em condições de, avançando na nossa investigação, apreender mais plenamente o modo benjaminiano de entender a autoria. Ali, no clímax da frase, se faz presente uma figura muito significativa: o leitor. Esta figura, ao ser assim fusionada com a de autor, agiganta, expande, magnífica, tudo o que até aqui dissemos. Pois sua introdução significa que todos, todos, são autores ${ }^{17}$. As barreiras agora desaparecem por completo. O leitor é qualquer um; não estão absolutamente em consideração quaisquer "credenciais" prévias. Basta ser produtor.

Benjamin nunca dominou o russo, mesmo após sua estada na União Soviética. Deste modo, sua visão da imprensa daquele país é mediatizada. Sua fonte é Sergei Tretiakov, cuja experiência conheceu através da leitura de sua obra autobiográfica $O s$ generais, escrita a partir das iniciativas transformadoras que o autor pôs em prática

\footnotetext{
12 Ibid, p. 129

${ }^{13}$ Ibid, p. 129

${ }^{14}$ Ibid, p. 124

${ }^{15}$ Ibid. p. 130

${ }^{16}$ Ibid. p. 125

${ }^{17}$ Já antes vimos que foram fusionadas as figuras de palco e público e as de intérprete e ouvinte. Mas não têm estas refuncionalizações, assim no-lo parece, a mesma força que a de autor e leitor, pois há ainda um quê de elitismo nas manifestações culturais de que aquelas são próprias. O jornal popular, panfletário, é considerado, ao contrário, um instrumento de conscientização das massas. Benjamin, o quererá das massas pelas massas.
} 
numa fazenda coletiva. A influência que segundo Benjamin teve este livro no desenvolvimento da economia coletivizada, torna Tretiakov exemplo de autor progressista. Isto é, de autor produtor, como vamos compreendendo. De autor cuja qualidade técnica consiste justamente na reordenação ou reorientação das funções dos trabalhadores, tirando-os do papel de objetos, de expectadores, de consumidores, e criando condições de participação, de protagonismo, por meio da palavra. Por quê? Porque o ato de relatar a própria experiência - a sua "literalização", na terminologia brechtiana adotada por Benjamin - repõe o homem no lugar que lhe pertence: no centro - pois "o homem está no centro de suas experiências". ${ }^{18}$ Também o movimento do dadaísmo devia sua força revolucionária, não só à consideração dada ao homem comum, segundo acima comentamos, como, sobretudo, à crença no poder que este tinha de produzir arte verdadeira.

Entretanto, posto o valor emancipatório e igualador da palavra, apresenta-se um desafio incontornável: o exercício do direito de se expressar, de procurar influenciar o rumo dos acontecimentos pela partilha da própria experiência, pressupõe a capacidade de fazê-lo. Para que todos efetivamente tenham acesso à condição de autor, para que o mundo do trabalho como um todo tome a palavra, será preciso que "a capacidade de descrever esse mundo [passe] a fazer parte das qualificações exigidas para a execução do trabalho". ${ }^{19}$ Só a superação da formação especializada estenderá a todos o "exercício da profissão literária". Desta agudíssima afirmação - na que lhe convido a deter-se, para, com vagar, deixá-la reverberar no seu imo, até lhe captar toda a sua grandeza -, desta afirmação, dizíamos, julgamos poder extrair uma conclusão válida para qualquer época e lugar: a formação científico-técnica (que é a que predomina entre nós, impulsionada por governos de todo o espectro político) pode tornar uma sociedade mais competitiva; até mais rica. Mas, sem o desenvolvimento cultural e o aumento da capacidade de compreensão e expressão oral e escrita, a sociedade como um todo permanecerá na minoridade. Um povo afásico nunca fará política - nas ruas, nos ofícios, nas artes. Um povo que não faz política não será um povo livre. Só a capacidade de ocupar o centro, de expor a si mesmo, de fazer propostas em relação a todos os aspectos da existência pode aplainar as divisões entre as classes, revolucionando, humanizando as relações sociais. "Em suma", nos diz Benjamin, "é a literalização das condições de vida que resolve as antinomias" ${ }^{20}$. Numa frase, todo um programa político!

Pensamos que, chegados a este ponto, fica claro, no pensamento de Walter Benjamin, o ideal de abertura à palavra do outro, tornado por meio dela um igual. Ideal que se constitui em princípio operativo de justiça social, ou "socialista", se se preferir. É interessante encontrar um eco deste ideal no conceito escolástico de justiça, expresso na figura de Tomás de Aquino. Para o Aquinate, justiça era essencialmente abertura e igualação. Abertura porque, residindo na parte mais nobre da alma, essa virtude abria o homem às necessidades dos outros; igualação porque, como a própria palavra indica justiça vem de "ajustar", tornar iguais -, seu fim na sociedade era a de realizar o ajustamento das relações no interior da comunas, da sociedade. Tomás e Marx leram a Aristóteles. Benjamin leu a Marx... Não, não é uma tese. Nem mesmo uma conjetura. Mas é verdade que na grande teia do pensamento tudo pode ser explicado em termos de tudo. Benjamin era mestre em navegá-la. Compreendia a lógica da rede. Antes da Internet, fazia já do entrecruzamento de idéias, linkando com desenvoltura um pensamento a outro, a expressão concreta da inovação técnica que exigia no ofício do

\footnotetext{
${ }^{18}$ Ibid. p. 134

${ }^{19}$ Ibid. p. 125

${ }^{20}$ Ibid, 124
} 
autor-produtor. Seu texto - bricolagem assistemática, imprevisível, fugaz - desborda a ordem convencional. O uso intenso que hoje se faz de suas iluminações críticas nos mais variados campos da cultura - em abono das proposições mais contraditórias evidencia que soube derrubar os muros entre eles.

Em A modernidade, cita Baudelaire na descrição de uma grande cidade como "malha de inúmeras relações entrelaçadas" ${ }^{21}$. A grande cidade é hoje a polis planetária, o denso tecido de relações dinâmicas e heterogêneas que tudo absorve. Entretanto, o capital, as necessidades de produção e a mercantilização de todos os conteúdos mantêm também nela, ainda hoje, sua hegemonia. A comunicação, em muito maior grau que nos anos trinta, abusa do efeito narcotizante das imagens, que excitam os sentidos, mas embotam a consciência. Como de habitual, alguns continuam a ver sintomas de desagregação na burguesia decadente, prenunciando o fim do atual estado de coisas. Outros, já, benjaminianamente, enxergam virtualidades significativas na nova realidade interconectada. Recentemente ${ }^{22}$, a revista Time escolheu uma blogueira chinesa entre as cem pessoas mais influentes do planeta. Zeng Jinyan, uma pessoa comum, ativista dos direitos humanos, rompe com seu blog os compartimentos estanques entre as funções, fundindo leitores e autores, produzindo em conjunto um espaço de literalização de suas experiências que derruba barreiras políticas e geográficas, a par que promove a justiça mediante propostas de reorganização dos direitos dos trabalhadores de seu país. Tudo isso ela o diz ao mundo com a máxima simplicidade, definindo sua meta como sendo a de "impulsionar que na China haja uma sociedade civil, com mais facilidades para o associacionismo e mais liberdade para opinar". Será Zeng Jinyan uma leitora de Walter Benjamin? É mais provável que as idéias deste, ricocheteando de nó em nó infinitamente reapropriado, resemantizado, metamorfoseado; uma e outra vez resgatados seus fragmentos e tornados contemporâneos - ecoe sutil, mas eficazmente, no recôndito de sua consciência política.

Para concluirmos, devemos acrescentar uma última nota, porém fundamental, àquele conceito de autoria que nos propusemos caracterizar. Talvez você, autor, sinta que sua produção intelectual preenche as elevadas exigências que fizemos até aqui. Não, você não é apenas um "intelectual puro", que no fundo "fala em nome do fascismo"; mas alguém que prova sua autenticidade revolucionária podendo responder afirmativamente a estas duas decisivas perguntas:

Consegue promover a socialização dos meios de produção intelectual? Vislumbra caminhos para organizar os trabalhadores no próprio processo produtivo? ${ }^{23}$

Sim! Você é então um autor progressista. Um autor produtor. Suas propostas transformam a realidade, abolem limites, resgatam a dimensão política das pessoas comuns, promovem aprendizagem libertadora. E faz tudo isso construindo espaços vitais, horizontais, plenos de interação, igualitários, desalienadores, geradores de uma nova consciência. Mas o protagonista desses novos espaços criados

\footnotetext{
${ }^{21}$ Id, A Modernidade, in A modernidade e os modernos, $2^{\mathrm{a}}$. Edição, Rio de Janeiro, Tempo Brasileiro, 2000 , p. 6

${ }^{22}$ Cf. http://www.time.com/time/magazine/article/0,9171,1617552,00.html

${ }^{23}$ Benjamin, Walter, $O$ autor como produtor in Magia e técnica, arte e política, op. cit., p. 136
} 
com seu concurso não é mais você. São todos. Porque, agora, todos os produtores são já atores. É preciso, pois, que caia a última distinção: a que separa o autor como produtor dos produtores atores. É preciso que você, autor produtor, baixe também à platéia, onde sua inteligência "há de desaparecer. Porque a luta revolucionária não se trava entre o capitalismo e a inteligência, mas entre o capitalismo e o proletariado". ${ }^{24}$

Talvez, como dissemos ao início, atrevermo-nos a falar em "conceito de autoria" tenha sido trair o pensamento de Benjamin. Mas é o dele também um pensamento que trai, que condena a si próprio ao anunciar, como acabamos de ver, que será fatalmente devorado por seus filhos; que, na batalha final entre capitalistas e proletários, os conceitos da inteligência, como qualquer produto intelectual, não mais terão vez. Deveremos incluir aqui também o conceito de autor como produtor? Na medida em que o fizermos, teremos de reconhecer em Benjamin uma espécie de fúnebre clarividência: de fato, nas sociedades varridas pelo vento revolucionário (leia-se: submetidas à tutela soviética) muito do inerente à sociedade burguesa foi arrancado de raiz; notadamente, a liberdade de pensamento e de sua expressão - pré-requisitos da autoria - foram implacavelmente cerceados. É a derradeira contradição dialética: o revolucionário conceito de autor como produtor só subsiste enquanto perdura a sociedade burguesa, contra cujas estruturas milita. Admitamos então o paradoxo: é no cultivo das contradições, é na barroca convivência dos contrastes que reside o secreto da permanência e da vitalidade; e isso vale tanto para as sociedades, tanto para a burguesa pirâmide de poder, como para os indivíduos, como para Walter Benjamin, seu modo de pensar e sua proposta política centrada na figura do produtor-autor.

As estruturas da sociedade burguesa experimentam nos dias atuais uma profunda reorganização impulsionada por tecnologias que fundem o planeta num todo horizontal onde desaparecem boa parte dos limites, barreiras e distinções que compunham o mapa humano. Todas as ordens - política, cultural, econômica - sofrem um processo de redefinição acelerada e imprevisível por obra da configuração em grau extremo da nossa sociedade como efetiva "malha de inúmeras relações entrelaçadas". Exemplo emblemático dessa nova realidade é a tecnologia "wiki", da qual a enciclopédia Wikipedia é sua concretização pioneira e mais conspícua. Não falta ali, claro, a Benjamin um verbete nas principais línguas. Seus autores? Quem o sabe? Produtores. Potencialmente e a qualquer momento, você ou eu, que podemos editar - reescrever mesmo - o que está escrito para completá-lo ou contradizê-lo. Para quebrar suas definições com dados que desbordem seus limites ou para confrontá-las com interpretações antagônicas, ou com os insights mais disparatados. Temos essa liberdade. Demos um salto quântico entre a época do leitor-consumidor-de conteúdos-prontos e a do leitor-publicador, antevista e preconizada por Benjamin. Nos dias de hoje, a cultura de rede, potenciada por gerações de jovens que aprenderam a usar o computador antes mesmo de ser alfabetizados, que vivem e estudam, trabalham e amam interconectados, está redesenhando todos os âmbitos da atividade humana - inclusive o político. $\mathrm{O}$ mundo - e perdoe-se, ao menos neste contexto, essa benjaminiana falta de pessimismo transforma-se a passos agigantados num espaço único de convivência plural, naturalmente heterodoxo, ilimitadamente variegado, sem as fronteiras - que o são antes do pensamento - cuja tentativa de transposição custaram a vida a Benjamin.

\footnotetext{
${ }^{24}$ Ibid, p. 136
} 
Algumas páginas acima, enquanto íamos tratando de desenovelar o fio da compreensão benjaminiana sobre o potencial libertador da palavra, vimos que este não se manifesta na palavra por si só, mas sim, somente, na que se serve de inovações técnicas em seu propósito refuncionalizador. Nos últimos dias noticiou-se que um de cada quatro internautas chineses têm um blog, isto é, um a modo de diário eletrônico onde relata, literaliza, compartilhando-as, suas experiências, modos de ver a realidade, divagações... questionamentos... críticas... propostas de alternativas. Hoje, os analistas políticos de todos os quadrantes se devotam ao escrutínio de todos os aspectos da trajetória desse sempre enigmático país, pois, dadas suas colossais dimensões, qualquer feição do seu desenvolvimento terá um impacto marcante no resto do globo. Esses dedicados analistas deveriam tomar boa nota desta estatística sobre os blogs. É, possivelmente, o indicador mais significativo, mais diáfano, do futuro daquela nação. Para entendê-lo, contudo (e para não se deixar cegar por estendidos e muito acadêmicos preconceitos em relação às novas tecnologias em geral, a aos blogs em particular) é necessário compreender o que é um blog - fazendo e respondendo a filosófica pergunta pela sua natureza, sua essência. Pois bem, o que cada blog em si é, é autoria. A ousadia da autoria; ou melhor: da co-autoria. Porque um blog, não só tecnicamente como proceduralmente, é uma miscelânea de referências, uma cacofonia de recitações onde cada pensamento se constrói transversalmente a incontáveis outros. Cada conexão, a tecer condutos de sentido entre os textos de diversos autores, torna o conjunto da malha mais espessa, mais intensa, mais vital, mais auto-organizada e evolutiva; mais forte mais capaz, em conseqüência, de desafiar e até abater, não se duvide disso, uma das ultimas ditaduras do pensamento único, oficial, monoforme, do planeta. $\mathrm{O}$ fecundo casamento de palavra e tecnologia torna de mão única e irrefreável a via da liberdade. Nesta semana, as autoridades daquele país anunciaram o afrouxamento dos controles e a suspensão da censura a alguns sites - a Wikipedia, entre eles - até o final das Olimpíadas (...) a serem ali sediadas, em breve. É um sintoma de debilitamento, uma recuada de terreno que não lhes será fácil reaver. O diálogo é o sangue da democracia, e, transfusões como essa revigoram a capacidade de um povo de recusar o retorno à concentração, à supervisão, à verdade pasteurizada e à doutrinação monocórdia.

Também conta-se em dias o anúncio quase paralelo das autoridades cubanas, logo após a sucessão na dinastia dos Castro, da permissão à população de comprar computadores. Cuba é o zero da autoria: nesse pedaço caribenho sob o totalitarismo marxista-leninista, os livros de Walter Benjamin, assim como os da totalidade dos marxistas críticos, estão proibidos ${ }^{25}$. Cuba é minúscula, e praticamente insignificante, em comparação a China, e mesmo em comparação a qualquer outro país ocidental. Paupérrima, sobrevive da mesada dos cubanos no exílio. Mas, no imaginário desse mesmo Ocidente, ou talvez, do mundo todo, tem uma importância desproporcional, capaz até de eclipsar o país amarelo. O el paredón é mais famoso que a Grande Muralha. O cubanizado Ché tem mais mística que Confúcio, Fidel é mais retratado que toda a octogenária liderança chinesa, incluindo Mao. O charuto daquele é mais de esquerdas que o Livro Vermelho deste. Sierra Maestra e La Revolución têm suscitado incomparavelmente mais paixão que a Grande Marcha ou a Revolução Cultural. Cuba é, insofismavelmente, o ícone da rebelião contra o sistema; o romantismo da política, a insígnia do marxismo impenitente, o flerte de todas as esquerdas, a última praça forte ante o sítio do capitalismo, o Pasárgada dos que sonham com o radicalmente diferente. Em Cuba, dizíamos, estão a vender ao povo computadores - logo esse paroxismo da reprodutibilidade técnica. Noticiou-se que há filas de espera. É o fim. Assim que os

\footnotetext{
${ }^{25}$ Cf. Rojas, R. Benjamin no llegó a La Habana, El País, 04/07/2006, in http://www.elpais.com/articulo/elpporopi/20060704elpepiopi_6/Tes/Benjamin/lleg\%F3/Habana
} 
hermanos forem tocados com o vírus do cosmopolitismo, da escolha pessoal, do pinçamento por cada um do que crêem ter valor no meio à mixórdia incontrolável de todas as opiniões e pareceres, propagandas e apostolados - assim que os cubanos passearem na Paris do ciberespaço, e se enredarem nos infindos tentáculos da medusa Internet para ali relatar mutuamente seus modos de ver a vida na ilha - assim que coisas corriqueiras como essas acontecerem dia após dia, estará fixada a data em que a aura inimitável de Cuba - eterna como a de todas as experiências humanas que entraram na Mitologia dos povos - será já, porém, a de uma história em destroços. Mas o anjo de Klee não o lamenta - nada se perde, tudo se resgata e se remoderniza, se restaura e se retransmite, vira remake e se reexibe, no poliédrico labirinto de galerias, vitrines de proselitismo e espelhos de todos os tempos e lugares que é o mundo virtual. Neste, os mudos flâneurs perdem espaço para os autores, para os que têm o que narrar, para os que querem dizer algo de si ao mundo, para os que bradam nas ágoras cibernéticas, para os que semeiam palavras, propalam idéias, aventam propostas, agitam projetos. No vórtice da Internet, como na "massa líquida incandescente" de Benjamin, tudo se fusiona no magma verbal, expelido, na ânsia inesgotável de se expressar, pelo homo loquens.

Vivemos - é um fato - na que é cada vez mais a "sociedade da autoria". Vivemos na mais benjaminiana das sociedades.

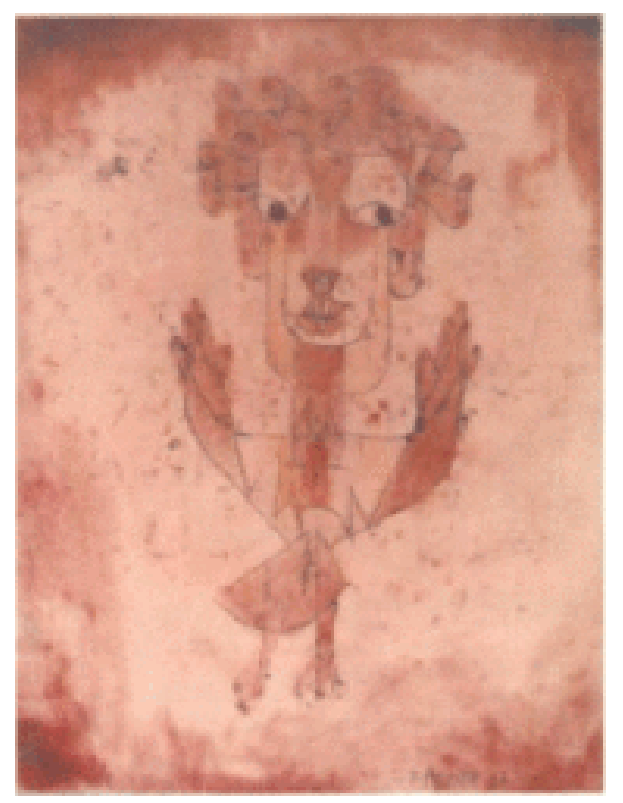




\section{Referências Bibliográficas}

1. BENJAMIN, Walter. A Modernidade, in A modernidade e os modernos, $2^{\mathrm{a}}$. Edição, Rio de Janeiro, Tempo Brasileiro, 2000.

2.------- Crítica da Violência: critica do poder (Trad. Willi Bolle), in http://antivalor.vilabol.uol.com.br/textos/frankfurt/benjamin/benjamin_index.html

3.--------------Magia e técnica, arte e política (Trad. Sérgio Paulo Rouanet), São Paulo, Brasiliense, 1996

4. COETZEE, J.M. As maravilhas de Walter Benjamin (trad. Siqueira, R.), pub. orig. The New York Review of Books, vol. 48, $\mathrm{n}^{\circ}$ 1, janeiro de 2001, in http://www.cebrap.org.br/imagens/Arquivos/as_maravilhas_de_walter_benjamin.pdf

5. ROJAS, R. Benjamin no llegó a La Habana, El País, 04/07/2006, in http://www.elpais.com/articulo/elpporopi/20060704elpepiopi_6/Tes/Benjamin/lleg\%F3/ Habana

6. WIKIPEDIA, Walter Benjamin, in http://en.wikipedia.org/wiki/Walter_Benjamin 